\title{
The experiences of acute non-surgical pain of children who present to a healthcare facility for treatment: a systematic review protocol
}

\author{
Nicole Pope ${ }^{1,2,3}$ \\ Mary Tallon ${ }^{3}$ \\ Ruth McConigley ${ }^{3}$ \\ Sally Wilson ${ }^{1,2,3}$
}

1 Princess Margaret Hospital for Children, Child and Adolescent Health Service, Perth, Australia

2 West Australian Centre of Evidence Informed Healthcare Practice: a Collaborating Center of Joanna Briggs Institute, Curtin University, Perth, Australia

3 School of Nursing, Midwifery and Paramedicine, Curtin University, Perth, Australia

Corresponding author:

Nicole Pope

Nicole.pope@postgrad.curtin.edu.au

\section{Review question/objective}

The qualitative objective of this systematic review is to identify and synthesize the best available evidence on experiences of acute non-surgical pain, including pain management, of children (between four to 18 years) when they present to a healthcare facility for treatment.

The specific objectives are to identify:

- Children's experiences of their acute, non-surgical pain, including pain management

- Children's expectations of others in managing their acute, non-surgical pain including, but not limited to parents and nurses

\section{Background}

The International Association for the Study of Pain defines pain as "an unpleasant sensory and emotional experience associated with actual or potential tissue damage or described in terms of such damage". ${ }^{1(\mathrm{p} 2701)}$ The pain experience is multifaceted and complex, extending beyond the physiological interpretation of a noxious stimulus, encompassing other dimensions, including; psychological, cognitive, sociocultural, affective and emotional factors. ${ }^{1-3}$ Pain can be described as chronic (persisting for three months or more) or acute (a time limited response to a noxious stimuli). ${ }^{4}$ Over the past 50 years clinical research has made revolutionary contributions to better understanding pediatric pain. The once pervasive erroneous notion that infants do not experience pain the same way as adults has been firmly dispelled. We now know that nervous system structures associated with the physiological interpretation of pain are functional as early as fetal development. ${ }^{5,6}$ Despite this critical knowledge and the growing global commitment to improving pediatric pain management in clinical practice, evidence repeatedly suggests that pain management remains suboptimal and inconsistent, a phenomenon commonly referred to as oligoanalgesia. ${ }^{7-10}$ Research evidence has linked poorly managed pain in the pediatric population to negative behavioral and physiological consequences later in life. ${ }^{5,6,11}$ Effective pain management is therefore a priority area for health care professionals. Improved understanding of children's experiences of acute non-surgical pain may lead to improved pain management and a reduction in oligoanalgesia.

In the 1970s and 1980s, studies began exploring the subjective experiences of pediatric pain and discovered children's abilities to articulate their pain experiences, and to link causes and 
consequences of their pain. ${ }^{12-14}$ Developmental trends or age related patterns with regards to children's expressions and experiences of pain were identified. ${ }^{13}$ Recent studies have also recognized apparent trends in children's understanding and expressions of pain; these follow an age and cognitive development trajectory in line with Piaget's theories of development. ${ }^{2,5,15}$

For many children psychosocial aspects of pain, including emotions like fear, stress and anxiety, are often more unpleasant than the painful experience itself. ${ }^{1,2,11,16}$ Emotional responses such as distress and anxiety are commonly associated with the anticipation of pain, can exacerbate and intensify the pain experience,$^{17}$ and can significantly lower a child's pain threshold. ${ }^{11}$ One study utilized an observational pain assessment tool to explore children's pain experiences. The findings indicated that children who underwent "non-painful" procedures (such as restraint) had equal, and in some cases higher, pain scores than those who underwent painful procedures (such as intravenous cannulation). ${ }^{11}$

Several studies exploring pediatric pain within health care settings (including, but not limited to, general practitioners, hospitals, emergency departments and outpatient clinics) have adopted quantitative methods, ${ }^{7,} 11,18$ some examined parents' perspectives, ${ }^{19,}{ }^{20}$ and others explored nurses' perceptions. ${ }^{21,22}$ While results of such studies have added to the existing body of knowledge that supports the need to focus on improving pediatric pain management, it has been suggested that failing to ask children directly risks not capturing subjective experiences of pain from the children's perspectives in their entirety. ${ }^{16,23}$ Seeking the children's perspectives could provide a more reliable and adequate means of gaining insight into their needs and expectations when they are in pain.

A single centered study in Singapore used semi-structured face-to-face interviews $(n=15)$ to explore children's experiences of pain management postoperatively. While the children, aged between six and 12 years, identified the role of analgesia in managing their pain, they also placed significant emphasis on the role of parents and health care professionals in implementing non-pharmacological interventions in pain management. ${ }^{24}$ These results are relevant as they provide insights into how children experience and express pain, and their expectations of health care professionals in managing their pain. These findings draw attention to effective pain management approaches when caring for children. Similarly, a UK study adopted a cross sectional descriptive design using the draw and write technique aimed at investigating children's views on what helped when they were in pain. The children $(n=71)$ were aged between four and 16 years. Findings revealed that children viewed themselves as active agents in pain management, while also placing significant emphasis on the importance of parents and nurses in managing their pain. ${ }^{25}$ In both studies, children valued nurses for social interactions, such as kindness and humor, rather than the provision of clinical care, including analgesia administration. Adjunct therapies such as distraction, visualization and music have also been shown to be effective in managing the pain experience in children. ${ }^{26}$

Not only do these findings demonstrate the complexity of the pain experience for the child, they also support the notion that improved pain management may come from research that is designed to better understand the entire pain experience from the child's perspective. While there are systematic reviews on interventions for managing children's pain, ${ }^{27,28}$ and one explored children's experiences in the postoperative context, ${ }^{29}$ none have considered children's experiences of acute non-surgical pain when they present for treatment. This qualitative systematic review aims to identify and synthesize results of studies exploring children's experiences of pain and pain management.

\section{Keywords}

children; experience; pain management acute pain; qualitative research

\section{Inclusion criteria}

\section{Types of participants}

This review will consider studies that include children aged four to 18 years who present to a healthcare facility for treatment of their acute (less than three months), non-surgical pain caused by any injury or medical condition. Children younger than four years typically have not developed linguistic skills that enable them to articulate their experiences. ${ }^{30,31}$ 


\section{Phenomena of interest}

This review will consider studies that explore children's experiences of acute, non-surgical pain and their expectations of other people in managing their pain, including, but not limited to, parents and nurses.

\section{Context}

Any healthcare facility, including, but not limited to, general practitioners, hospitals, emergency departments and outpatient clinics will be considered.

\section{Types of studies}

This review will consider studies that focus on qualitative data, including, but not limited to, designs such as phenomenology, grounded theory, ethnography, action research and feminist research.

\section{Exclusion criteria}

Studies focusing on children with postoperative pain, or those reporting on children with chronic pain will be excluded.

\section{Search strategy}

The search strategy aims to find both published and unpublished studies. A three-step search strategy will be utilized in this review. An initial limited search of MEDLINE and CINAHL will be undertaken followed by an analysis of the text words contained in the title and abstract, and of the index terms used to describe the article. A second search using all identified keywords and index terms will then be undertaken across all included databases. Thirdly, the reference list of all identified reports and articles will be searched for additional studies. Studies published in English will be considered for inclusion in this review. Studies published from 2000 to 2015 will be considered for inclusion in this review. From the late 1990s Family Centered Care which incorporates models of care where healthcare professionals no longer assume an expert role and work in partnership with families, ${ }^{32}$ were introduced into pediatric healthcare. This shift from a more prescriptive model to a partnership model is well supported in preceding literature. ${ }^{33,}{ }^{34}$ Therefore, acknowledging that children's perceptions on aspects of their healthcare are important and studies have been undertaken on this phenomenon from 2000.

\section{The databases to be searched include:}

CINHAHL

MEDLINE (PubMed)

Scopus

ScienceDirect

PsycINFO

ProQuest

Embase

Web of Science

The search for unpublished studies will include:

Google Scholar

Mednar

ProQuest Dissertations and Theses

Initial keywords to be used will be: 


\section{Children*}

Child $^{*}$

Paediatric

Pediatric

Experience*

Perception*

Pain*

Acute

\section{Assessment of methodological quality}

Qualitative papers selected for retrieval will be assessed by two independent reviewers for methodological validity prior to inclusion in the review using standardized critical appraisal instruments from the Joanna Briggs Institute Qualitative Assessment and Review Instrument (JBI-QARI) (Appendix I). Any disagreements that arise between the reviewers will be resolved through discussion, or with a third reviewer.

\section{Data extraction}

Qualitative data will be extracted from papers included in the review using the standardized data extraction tool from JBI-QARI (Appendix II). The data extracted will include specific details about the interventions, populations, study methods and outcomes of significance to the review question and specific objectives.

\section{Data synthesis}

Qualitative research findings will, where possible, be pooled in a meta-synthesis using JBI-QARI. This will involve the aggregation or synthesis of findings to generate a set of statements that represent that aggregation through assembling the findings (Level 1 findings) rated according to their quality and categorizing these findings on the basis of similarity in meaning (Level 2 findings). These categories will then be subjected to a meta-synthesis to produce a single comprehensive set of synthesized findings (Level 3 findings) that can be used for evidence based practice. Where pooling is not possible, the findings will be presented in narrative form.

\section{Conflicts of interest}

There are no conflicts of interest to declare.

\section{Acknowledgements}

The authors would like to acknowledge the Princess Margaret Hospital Foundation for the Seeding Grant supporting this research. The authors would also like to thank the Curtin University's librarians for their contribution to the search strategy. 


\section{References}

1. Ortiz MI, López-Zarco M, Arreola-Bautista EJ. Procedural pain and anxiety in paediatric patients in a Mexican emergency department. J Adv Nurs. 2012;68(12):2700-9.

2. Atherton T. Children's experiences of pain in an accident and emergency department. Accid Emerg Nurs [Internet]. 1995 [cited 2014 Aug 15]; 3(2):[79-82 pp.]. Available from: https://login.pklibresources.health.wa.gov.au/login?url=http://search.ebscohost.com/login.aspx?direct $=$ true $\& \mathrm{db}=\mathrm{rzh} \& \mathrm{AN}=1995028436 \&$ site $=$ ehost-live \&scope=site.

3. Gyland EA. Infant pain assessment: A quality improvement project in a level III neonatal intensive care unit in Northeast Florida. Newborn Infant Nurs Rev [Internet]. 2012 3// [cited 2015 July 21]; 12(1):[44-50 pp.]. Available from: http://www.sciencedirect.com/science/article/pii/S1527336911001917.

4. Pain Australia. National Pain Strategy: Pain Management for all Australians Tamarama: Pain Australia 2011.

5. Drendel AL, Kelly BT, Ali S. Pain assessment for children: overcoming challenges and optimizing care. Pediatr Emerg Care [Internet]. 2011 [cited 2014 Aug 15]; 27(8):[773-81 pp.]. Available https://login.pklibresources.health.wa.gov.au/login?url=http://search.ebscohost.com/login.aspx?direct $=$ true $\& \mathrm{db}=\mathrm{rzh} \& \mathrm{AN}=2011237916 \&$ site $=$ ehost-live $\&$ scope $=$ site.

6. Akuma AO, Jordan S. Pain management in neonates: a survey of nurses and doctors. J Adv Nurs. 2012;68(6):1288-301.

7. Scott LE, Crilly J, Chaboyer W, Jessup M. Paediatric pain assessment and management in the emergency setting: The impact of a paediatric pain bundle. Int Emerg Nurs. 2013;21(3):173-9.

8. Bailey B, Gravel J, Daoust R. Reliability of the visual analog scale in children with acute pain in the emergency department. Pain (03043959) [Internet]. 2012 [cited 2014 Aug 15]; 153(4):[839-42 pp.]. Available from: https://login.pklibresources.health.wa.gov.au/login?url=http://search.ebscohost.com/login.aspx?direct $=$ true $\& \mathrm{db}=\mathrm{rzh} \& \mathrm{AN}=2011493362 \&$ site $=$ ehost-live \&scope $=$ site. .

9. Crocker PJ, Higginbotham E, King BT, Taylor D, Milling TJ. Comprehensive pain management protocol reduces children's memory of pain at discharge from the pediatric ED. Am J Emerg Med. 2012;30(6):861-71.

10. Drendel AL, Brousseau DC, Gorelick MH. Pain assessment for pediatric patients in the emergency department. Pediatrics [Internet]. 2006 [cited 2014 Aug 15]; 117(5):[1511-8 pp.]. Available from:

https://login.pklibresources.health.wa.gov.au/login?url=http://search.ebscohost.com/login.aspx?direct $=$ true \&db=rzh\&AN=2009194458\&site=ehost-live\&scope=site.

11. Babl FE, Crellin D, Cheng J, Sullivan TP, O'Sullivan R, Hutchinson A. The use of the faces, legs, activity, cry and consolability scale to assess procedural pain and distress in young children. Pediatr Emerg Care. 2012;28(12):1281-96.

12. Unruh A, McGrath $P$, Cunningham SJ, Humphreys P. Children's drawings of their pain. Pain (03043959). 1983;17(4):385-92.

13. Gaffney A, Dunne EA. Developmental aspects of children's definitions of pain. Pain (03043959). 1986;26(1):105-17.

14. Hurley A, Whelan EG. Cognitive development and children's perception of pain. Pediatric Nursing. 1988;14(1):21-4.

15. Esteve R, Marquina-Aponte V. Children's pain perspectives. Child Care Health Dev. 2012;38(3):441-52. 
16. Sutters KA, Savedra MC, Miaskowski C, Holdridge-Zeuner D, Waite S, Paul SM, et al. Children's expectations of pain, perceptions of analgesic efficacy, and experiences with nonpharmacologic pain management strategies at home following tonsillectomy. J Spec Pediatr Nurs [Internet]. 2007 [cited 2014 Aug 15]]; 12(3):[139-48 pp.]. Available from: Retrieved from direct=true $\& \mathrm{db}=\mathrm{rzh} \& A \mathrm{~N}=2009616904 \&$ site=ehost-live $\&$ scope $=$ site.

17. LeMay S, Johnston $\mathrm{C}$, Choinière $\mathrm{M}$, Fortin $\mathrm{C}$, Hubert I, Fréchette $\mathrm{G}$, et al. Pain management interventions with parents in the emergency department: a randomized trial. J Adv Nurs. 2010;66(11):2442-9.

18. Herd DW, Babl FE, Gilhotra Y, Huckson S. Pain management practices in paediatric emergency departments in Australia and New Zealand: a clinical and organizational audit by National Health and Medical Research Council's National Institute of Clinical Studies and Paediatric Research in Emergency Departments International Collaborative. Emerg Med Australas. 2009;21(3):210-21.

19. Pölkki T, Pietilä A-M, Vehviläinen-Julkunen K, Laukkala $H$, Ryhänen P. Parental views on participation in their child's pain relief measures and recommendations to health care providers. J Pediatr Nurs. 2002;17(4):270-8.

20. Simons J, Franck L, Roberson E. Parent involvement in children's pain care: views of parents and nurses. J Adv Nurs. 2001;36(4):591-9.

21. Griffin RA, Polit DF, Byrne MW. Nurse characteristics and inferences about children's pain. Pediatr Nurs. 2008;34(4):297.

22. Van Hulle Vincent C. Nurses' Perceptions of Children's Pain: A Pilot Study of Cognitive Representations. J Pain Symptom Manage. 2007;33(3):290-301.

23. Twycross A, Finley GA. Children's and parents' perceptions of postoperative pain management: a mixed methods study. J Clin Nurs. 2013;22(21/22):3095-108.

24. Sng QW, Taylor B, Liam JL, Klainin-Yobas P, Wang W, He HG. Postoperative pain management experiences among school-aged children: a qualitative study. J Clin Nurs. 2013;22(78):958-68.

25. Franck LS, Sheikh A, Oulton K. What helps when it hurts: children's views on pain relief. Child Care Health Dev. 2008;34(4):430-8.

26. Downey LV, Zun LS. The impact of watching cartoons for distraction during painful procedures in the emergency department. Pediatr Emerg Care. 2012;28(10):1033-5.

27. Shermin CYJSCW-CH-GH. Anxiety and pain in children undergoing elective surgical procedures: a systematic review: The JBI Library of Systematic Reviews. 10(29):1688-1737, 2012.; 2012.

28. Tan LMLLKSPYWK. Effective pain management during painful procedures in children with cancer: a systematic review: The JBI Library of Systematic Reviews. 12(4):430-484, 2014.; 2014.

29. Wen SQTBJLZH-GH. Children's experiences of their postoperative pain management: a qualitative systematic review: The JBI Library of Systematic Reviews. 11(4):1-66, 2013.; 2013.

30. Franck L, Noble G, Liossi C. From tears to words: the development of language to express pain in young children with everyday minor illnesses and injuries. Child Care Health Dev. 2010;36(4):524-33.

31. Stanford EA, Chambers CT, Craig KD. A normative analysis of the development of painrelated vocabulary in children. Pain (03043959). 2005;114(1-2):278-84.

32. Davis H, Day C, Bidmead C. Working in Partnership with Parents: the Parent Advisor Model. London: Harcourt Assessment; 2002.

33. Fowler C, Barnett B, McMahon C. Working with families : a relationship-based approach. Learning Links News. 2006(3):3-5. 
34. McKlindon HD, Barnsteiner HJ. Therapeutic relationships: evolution of the children's hospital of Philadelphia model. MCN, The American Journal of Maternal/Child Nursing. 1999;24(5):237-43. 


\section{Appendix l: Appraisal instruments \\ QARI appraisal instrument}

\section{JBI QARI Critical Appraisal Checklist for Interpretive \& Critical Research}

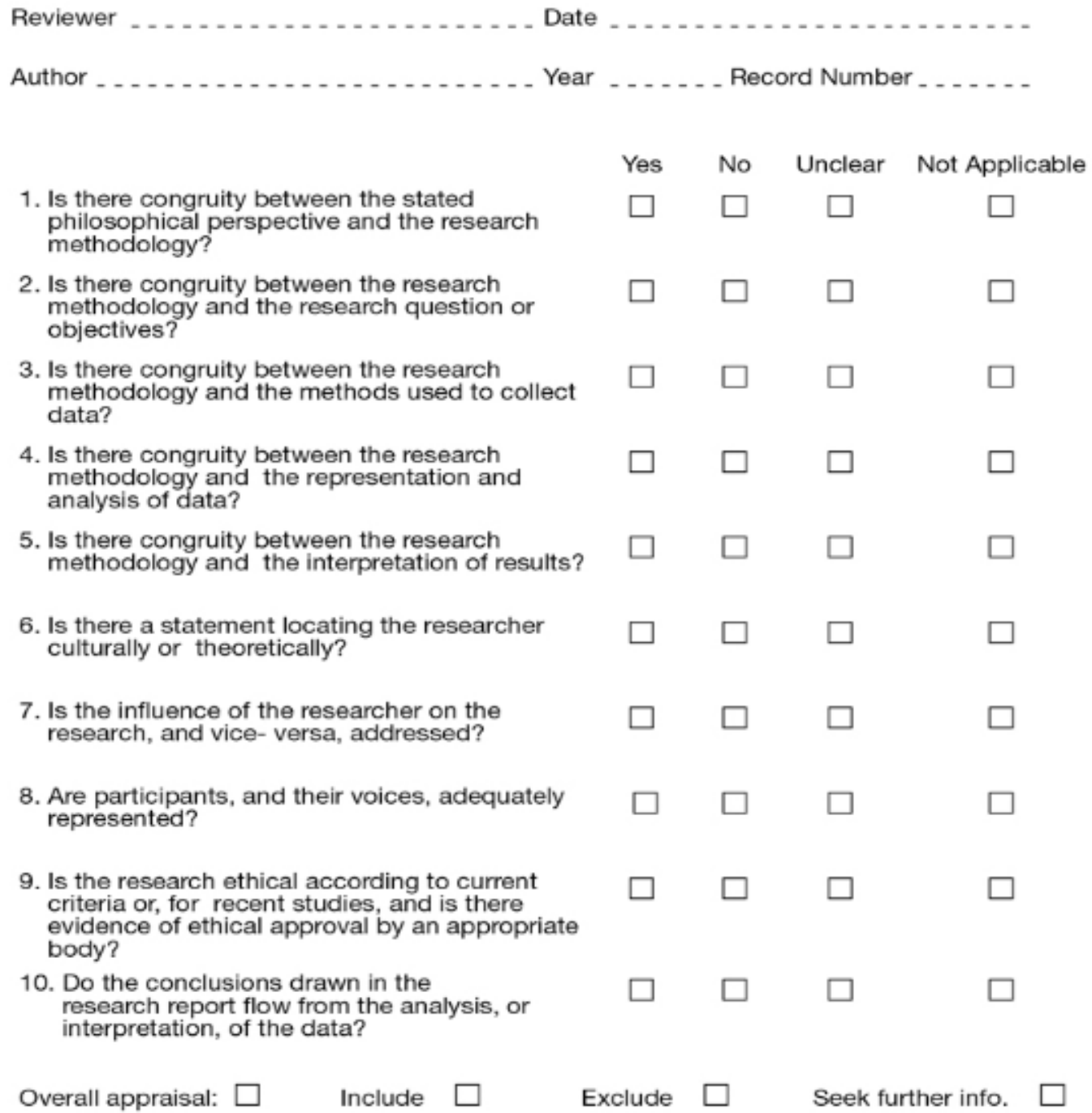

Comments (Including reason for exclusion)

\section{Appendix II: Data extraction instruments}

QARI data extraction instrument 


\section{JBI QARI Data Extraction Form for Interpretive \& Critical Research}

Reviewer $\ldots \ldots \ldots$
Author $\ldots \ldots \ldots$
Journal_ $\ldots \ldots \ldots$
Jear $\ldots \ldots \ldots$

\section{Study Description}

Methodology

Method

Phenomena of interest

Setting

Geographical

Cultural

Participants

Data analysis

Authors Conclusions

Comments

$\begin{array}{lll}\text { Complete } & \text { Yes } \square \quad \text { No } \square\end{array}$ 


\begin{tabular}{|l|l|l|l|l|}
\hline \multirow{2}{*}{ Findings } & \multirow{2}{*}{$\begin{array}{c}\text { Illustration from } \\
\text { Publication } \\
\text { (page number) }\end{array}$} & Unequivocal & Credible & Unsupported \\
\cline { 5 - 6 } & & & & \\
\hline & & & & \\
\hline & & & & \\
\hline & & & & \\
\hline & & & & \\
\hline & & & & \\
\hline & & & & \\
\hline & & & & \\
\hline & & & & \\
\hline
\end{tabular}

Extraction of findings complete Yes $\square$ No $\square$ 